\title{
Explaining the amount of care needed by hospitalised surgical patients: a prospective time and motion study
}

\author{
Catharina J van Oostveen ${ }^{1}$, Hester Vermeulen ${ }^{1,2}$, Dirk J Gouma ${ }^{3}$, Piet J Bakker ${ }^{1}$ and Dirk T Ubbink ${ }^{1,3^{*}}$
}

\begin{abstract}
Background: Hospitals provide care for patients with a variety of diseases, co-morbidities and complications. The actual amount of care these patients need is unclear. Given the recent developments such as ageing, multi-morbidity and budgetary restraints, a practical explanatory model would avail healthcare professionals and managers in determining the demand and costs for clinical care.

Methods: Six surgical wards in a Dutch university hospital participated in this prospective time and motion study. Surgeons, nurses and paramedics recorded the time spent on patient care 24/7 by means of PDAs. The investigators extracted possible determining characteristics from a previous systematic review and expert focus group. Total amount of care needed by the patients was expressed as costs involved in medical and nursing time, surgical interventions and diagnostics. Afterwards the investigators applied linear regression analysis to detect significant independent characteristics.

Results: 174 Surgical patients were monitored during their hospital stay. Characteristics significantly influencing the consumed amount of care were: medication during hospitalisation, complications, co-morbidity, medical specialty, age, as well as undergoing surgery and length of stay. Median costs for care were €8.446 per patient admission.

Conclusions: The investigators developed a model that explains the total demand and costs of care needed for surgical patients in a university hospital. The input for this instrument can be derived from readily available data in hospital databases. This makes it a relatively easy instrument to help healthcare professionals and managers appreciate the amount of care needed on (surgical) wards and may be used to appreciate trends in time.
\end{abstract}

Keywords: Patient characteristics, Workload, Time and motion research, (multiple) regression analysis

\section{Background}

Given the recent societal developments such as survival to an older age, increasing multi-morbidity and stagnating growth of the working population, it is expected that the demand for medical and nursing care will increase substantially [1]. Hospitals are nowadays more and more confronted with budget cuts and accountable to substantiate their costs spent on highly specialised, topreferral care. Therefore it is important for professionals and managers to identify the factors determining the

\footnotetext{
*Correspondence: d.ubbink@amc.nl

'Department of Quality Assurance \& Process Innovation, Academic Medical Centre, room A3-503, P.O box 22700, Amsterdam, DE 1100, The Netherlands ${ }^{3}$ Departments of Surgery, Academic Medical Centre, P.O box 22700,

Amsterdam DE 1100, The Netherlands

Full list of author information is available at the end of the article
}

(trends in the) demand and costs for care. Surgical wards of university hospitals in particular recognize the changing demography and increasing accountability, as they rely heavily on expensive facilities like operating theatres, ICUs, and diagnostic imaging.

Demand for care is defined as the needs of individual patients in terms of the sum of (para)medical and nursing resources used [2]. One of the seminal systems to measure and classify this demand for care from nursing resources is the Therapeutic Intervention Scoring System (TISS) [3]. This instrument helps classify the workload for nurses in the intensive care unit (ICU) by registering and weighing therapeutic nursing interventions. On general hospital wards, similar instruments are used as Patient Classification Systems (PCS). These

\section{Biomed Central}


instruments rely on subjective and clinical observations by nurses, give information about nursing care already given, and help with the staffing of nursing wards [4]. These instruments, however, cannot predict the demand for care, particularly from doctors and paramedics, and are not based on objective measures, such as patient characteristics.

Few studies have investigated objective influencing factors for nursing workload [2,5-14]. Although these studies applied the demand for care as a reference standard, they used different definitions for this entity $[15,16]$. This led to invalid and unreliable PCSs and systematic under- and overestimation of the demand for care, while the explored characteristics per se were poorly associated.

The investigators therefore aimed to develop an explanatory model, based on readily available clinical patient characteristics from hospital databases for the use of (para)medical and nursing resources by surgical patients. A practical explanatory model would avail healthcare professionals and managers in determining the demand and costs for clinical care and use this information for policy making, i.e., budget planning.

\section{Methods}

The conduct and description of this study was done according to the Suggested Time And Motion Procedures (STAMP) checklist [17].

\section{Setting}

Six general surgical wards in a university hospital in The Netherlands contributed to this study. These 24-bed wards provide standard and specialty surgical care, i.e. general, vascular, plastic, orthopaedic, and trauma surgery. On each ward approximately 30 nurses, three auxiliary nurses, one resident, two surgeons, one physical therapist, one social worker, and one dietician were involved during the study.

\section{Design}

In this prospective time and motion study medical, nursing and paramedical personnel continuously (24/7) recorded the patients' care process during admission.

The investigators recorded data on diagnostic and surgical procedures, intensive care stay, total length of hospital stay, and time spent on patient care by all caregivers (doctors, nurses and paramedics). Time recordings comprised direct patient contact or indirect care (i.e. patient-related telephone calls, planning and administrative activities, inter-professional consultations, multidisciplinary meetings, etc.). These data were used as reference standard to develop the desired explanatory model.

\section{Potentially predicting patient characteristics}

A set of 17 potentially predictive characteristics (Table 1) was defined based on suggestions made by a local expert panel (consisting of head nurses, nursing managers and clinicians), and a systematic literature review not yet published. These characteristics could be extracted from the medical and nursing files and hospital databases and therefore did not need any additional registration effort. Co-morbidities were counted if requiring treatment with drugs or medical devices (e.g. prosthesis).

Patient characteristics were collected and checked by two investigators independently during admission and after discharge from the hospital. Only co-morbidities requiring medication or a medical device were recorded. Missing data were retrieved from medical and nursing files or asked directly from the patients during their hospitalisation or, after discharge, by phone.

Table 1 Potentially predictive patient characteristic

\begin{tabular}{|c|c|}
\hline Characteristic & Range of possible values \\
\hline Surgical intervention & $0=$ yes, $1=$ no \\
\hline Date of birth & 0 to $\infty$ \\
\hline Gender & $0=$ woman, $1=$ man \\
\hline Number of co-morbidities & 0 to $\infty$ \\
\hline Number of complications & 0 to $\infty$ \\
\hline ASA-classification & $1,2,3$ or 4 \\
\hline BMl at admission & 0 to $\infty$ \\
\hline $\begin{array}{l}\text { Nutritional status (weight loss in past } \\
6 \mathrm{mo} \text {.) }\end{array}$ & 0 to $\infty \mathrm{kg}$ \\
\hline Delirium during hospitalisation & $0=$ no, $1=$ yes \\
\hline Pressure ulcer during hospitalisation & $\begin{array}{l}0=\text { no pressure ulcers, or grade } 1 \\
\text { through } 4 \text { ulcers }\end{array}$ \\
\hline Isolated care during hospitalisation & $\begin{array}{l}0=\text { no, } 1=\text { barrier, } 2=\text { strict } \\
\text { isolation }\end{array}$ \\
\hline Survival during hospitalisation & $0=$ yes, $1=$ no \\
\hline $\begin{array}{l}\text { Number of different medications } \\
\text { during hospitalisation }\end{array}$ & 0 to $\infty$ \\
\hline Admission type & $0=$ home, $1=$ emergency \\
\hline Discharge type & $0=$ home, $1=$ other \\
\hline Length of hospital stay & number of days \\
\hline \multirow[t]{8}{*}{ Surgical specialty } & TRAUMA Trauma surgery \\
\hline & URO Urology \\
\hline & SHORT Short Stay surgery \\
\hline & ORTHO Orthopaedics \\
\hline & ABDO G-I surgery \\
\hline & PLAST Plastic surgery \\
\hline & VASC Vascular surgery \\
\hline & $\begin{array}{l}\text { ORAL Oral and Maxillofacial } \\
\text { surgery }\end{array}$ \\
\hline
\end{tabular}




\section{Patient sample}

To define a patient sample representative for those regularly admitted to surgical wards, the investigators used the latest available update of the national medical registry (LMR) of admission diagnoses. To develop an explanatory model with up to 17 predefined characteristics, the investigators decided to collect a sample of at least 170 patients in a three-month period. The numbers of patients with a certain diagnosis to be included was commensurate with the ranking based on a top-12 of admission diagnoses for each ward (Table 2). Patient inclusion stopped when a sufficient number of patients with these diagnoses was reached.

\section{Study conduct}

For continuous time and motion research the investigators used Personal Digital Assistants (PDAs) (PalmOne Tungsten E2; Palm Inc., Sunnyvale, CA, USA). A dedicated software program was developed for this purpose (I-V-O: Web development, scripting, hosting \& consultancy, Alkmaar, The Netherlands). This allowed recording of the date, duration of direct and indirect time spent per patient, type of professionals involved, and wards and patients involved (Figure 1). Data thus collected were downloaded daily from the PDAs to a central computer database. The PDAs were distributed during every shift to the professionals involved on each ward. Consulting professionals visiting an included patient made use of an additional PDA placed at the patients' bedside. All professionals contributing to the study were informed about its purpose and the use of the PDAs by instructive posters and meetings.

Eight investigators distributed the PDAs and were available for support seven days a week from 7AM to midnight. Recording errors were as much as possible recognised directly by means of a logbook and corrected and evaluated afterwards. Recorded time data were checked and analysed twice a week for exceptional and missing values. Such recordings were replaced by an average, based on similar situations in the same patient. To check the reliability of the data the investigators frequently asked, and randomly shadowed, the professionals involved regarding their recording behaviour.

\section{Time and motion method}

To obtain a single measure for demand for care, information about wards, patient characteristics, professionals involved, date, time, and duration of care were converted into the costs involved. Standard costs for wages of the various professionals were used for day, evening, night, and weekend shifts, whenever applicable. Costs of surgical interventions were based on the gross time needed for the surgical procedure and the associated salary costs of the professionals present. The costs of diagnostic procedures and ICU and recovery stays were added to arrive at the total costs of the demand for care for each patient during their admission period. The total costs were used as the dependent variable in the explanatory model.

To account for the possible influence of the availability of resources on the amount of care given, the investigators also observed the relation between available Full Time Equivalents (FTE) and bed occupancy rates per ward.

\section{Statistical analysis}

Data were imported into the Statistical Package for the Social Sciences v. 16 (SPSS Inc., Chicago, IL, US). Categorical data are presented as proportions. Continuous variables are summarised as means with standard deviations.

After exploration of the association between the various characteristics and the costs of the demand for care in a univariable analysis, significant predictive characteristics were detected in a multiple backward linear regression analysis. Additionally, each non-significant factor was added one by one to the model found by the multiple backward analysis to check whether they contributed significantly to the model.

To distinguish patient characteristics and organisational factors, we analysed these in different models. For all analyses the significance level was set at $\mathrm{P}<0.05$. B-values were calculated with their 95\% confidence intervals. Log-transformation of the dependent variable total costs of demand for care was performed because of its non-normal distribution.

\section{Ethical issues}

Our local medical ethics review board (Academic Medical Centre, Amsterdam, The Netherlands) approved the study but waived the need for written informed consent, as the study had no effect on the patient's treatment or psychological wellbeing. Yet, all included patients received an explanation about the study and gave verbal consent.

\section{Results}

From February to April 2010, 174 consecutive patients were included, both elective and emergency admissions. One patient declined participation in the study. Demographics of included patients are summarised in Table 3.

Median total costs of the demand for care per patient were $€ 8,446$ and varied from $€ 815$ for trauma patients to $€ 82,780$ for G-I surgical patients (Figure 2). Surgical and diagnostic interventions contributed most to these costs. Nursing costs formed the largest part (76\%) of the personnel expenses; $€ 308$, vs. physicians $€ 56$, and paramedics $€ 2.70$ per patient, excluding the personnel 
Table 2 Patient samples per surgical specialty

\begin{tabular}{|c|c|c|c|c|}
\hline Specialty & Top 12 admission diagnoses & $\begin{array}{r}\text { Estimated diagnosis } \\
\text { incidence }\end{array}$ & $\begin{array}{r}\begin{array}{r}\text { Planned patient } \\
\text { inclusion }\end{array} \\
\end{array}$ & $\begin{array}{r}\text { Realised patient } \\
\text { inclusion }\end{array}$ \\
\hline URO & Diseases of the genitourinary system & $406(50.1 \%)$ & 23 & $(47.8 \%) 11$ \\
\hline \multirow[t]{4}{*}{ SHORT } & Diseases of the digestive system & $113(14 \%)$ & 7 & $(57.1 \%) 4$ \\
\hline & Neoplasms & $301(37.2 \%)$ & 17 & $(82.4 \%) 14$ \\
\hline & & & Additional inclusions & \\
\hline & Total & $810(100 \%)$ & 47 (100\%) & $(71.7 \%) 33(19 \%)$ \\
\hline VASC & Diseases of the circulatory system & $208(55.8 \%)$ & 12 & $(66.7 \%) 8$ \\
\hline \multirow[t]{6}{*}{ PLAST } & Diseases of the skin and subcutaneous tissue & $24(6.4 \%)$ & 1 & $(100 \%) 1$ \\
\hline & Diseases of the genitourinary system & $28(7.5 \%)$ & 2 & $(100 \%) 2$ \\
\hline & $\begin{array}{l}\text { Diseases of the musculoskeletal system and connective } \\
\text { tissue }\end{array}$ & $54(14.5 \%)$ & 3 & $(66.7 \%) 2$ \\
\hline & $\begin{array}{l}\text { Factors influencing health status and contact with } \\
\text { health services }\end{array}$ & $59(15.8)$ & 4 & (75\%) 3 \\
\hline & & & Additional inclusions & \\
\hline & Total & $373(100 \%)$ & $22(100 \%)$ & $(100 \%) 23(13.2 \%)$ \\
\hline \multirow[t]{5}{*}{ ABDO } & Neoplasms & $204(63 \%)$ & 12 & (125\%) 15 \\
\hline & Diseases of the digestive system & $106(32.7 \%)$ & 6 & $(133.3 \%) 8$ \\
\hline & $\begin{array}{l}\text { Factors influencing health status and contact with } \\
\text { health services }\end{array}$ & $14(4.3 \%)$ & 1 & $(200 \%) 2$ \\
\hline & & & Additional inclusions & 2 \\
\hline & Total & $324(100 \%)$ & 19 (100\%) & (142.1\%) 27 (15.5\%) \\
\hline ABDO & Neoplasms & $153(58.8 \%)$ & 10 & $(160 \%) 16$ \\
\hline \multirow[t]{4}{*}{ ORAL } & Diseases of the digestive system & $83(32 \%)$ & 5 & (300\%) 15 \\
\hline & $\begin{array}{l}\text { Injury, poisoning and certain other consequences of } \\
\text { external causes }\end{array}$ & $24(9.2 \%)$ & 1 & (300\%) 3 \\
\hline & & & Additional inclusions & 4 \\
\hline & Total & $260(100 \%)$ & $16(100 \%)$ & $(237.5 \%) 38(21.8 \%)$ \\
\hline \multirow[t]{4}{*}{ TRAUMA } & $\begin{array}{l}\text { Injury, poisoning and certain other consequences of } \\
\text { external causes }\end{array}$ & $311(88.1 \%)$ & 18 & $(66.7 \%) 12$ \\
\hline & $\begin{array}{l}\text { Diseases of the musculoskeletal system and connective } \\
\text { tissue }\end{array}$ & $42(11.9 \%)$ & 2 & (150\%) 3 \\
\hline & & & Additional inclusions & 9 \\
\hline & Total & $353(100 \%)$ & $20(100 \%)$ & $(120 \%) 24(13.8 \%)$ \\
\hline \multirow[t]{6}{*}{ ORTHO } & $\begin{array}{l}\text { Injury, poisoning and certain other consequences of } \\
\text { external causes }\end{array}$ & $124(27.2 \%)$ & 7 & $(57 \%) 4$ \\
\hline & $\begin{array}{l}\text { Diseases of the musculoskeletal system and connective } \\
\text { tissue }\end{array}$ & $286(62.7 \%)$ & 16 & $(113 \%) 18$ \\
\hline & Neoplasms & $46(10.1 \%)$ & 3 & $(133.3 \%) 4$ \\
\hline & & & Additional inclusions & 3 \\
\hline & Total & 456 (100\%) & 26 (100\%) & (111.5\%) 29 (16.7\%) \\
\hline & Overall total & & 150 (100\%) & (116\%) 174 (100\%) \\
\hline
\end{tabular}

costs for the surgical intervention. Median costs for surgical interventions were $€ 5,286$ (range: $€ 0 \quad-$ $€ 21,111)$. Median costs for diagnostic procedures were $€ 2,699$ and varied from $€ 372$ to $€ 74,567$ (Figure 3).

In the univariable analysis, age, number of complications, ASA-class, nutritional status, admission type, number of medications during hospitalisation, and surgical specialty were significantly associated with the costs of demand for care (Table 3), as opposed to gender, number of co-morbidities, and BMI. Delirium and isolation during hospitalisation, pressure ulcers, admission type, and mortality did not contribute 


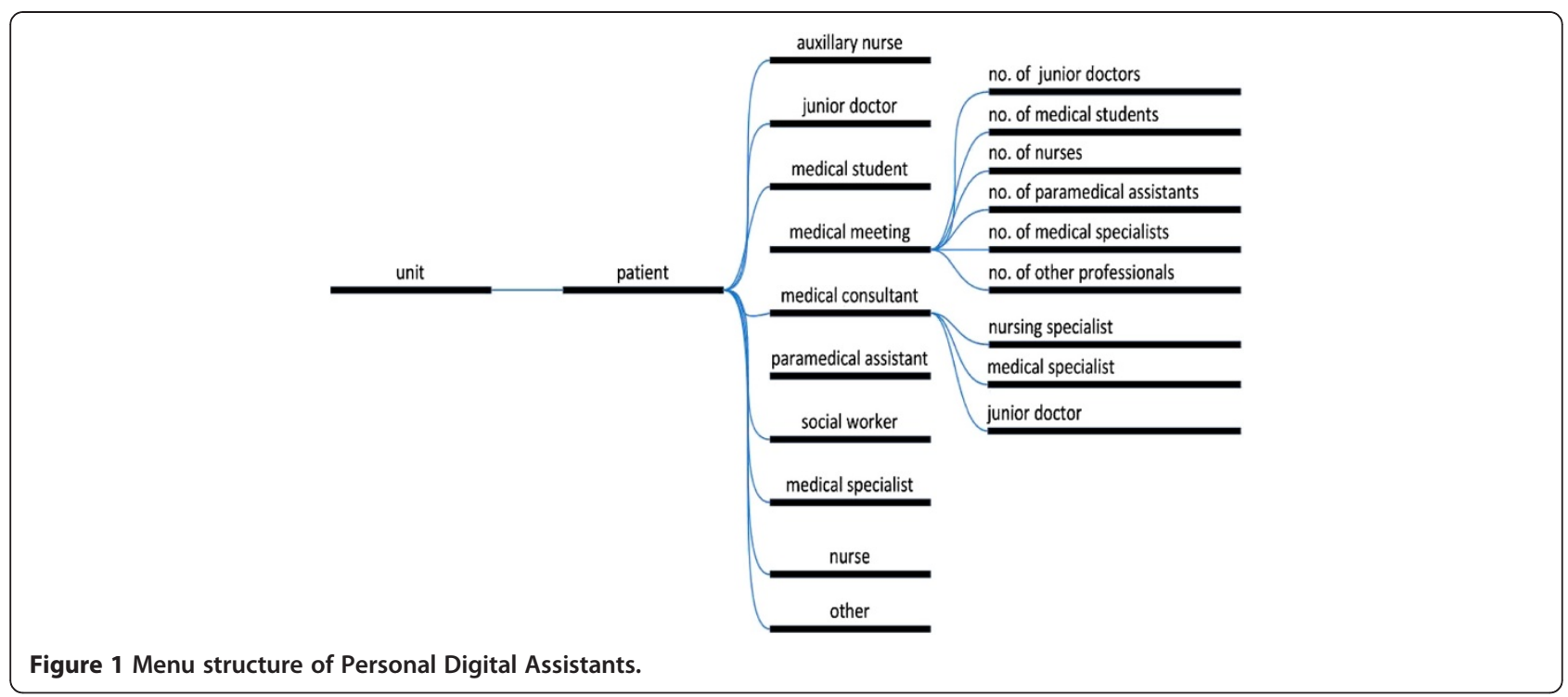

significantly, likely because they occurred rarely. A total of 153 valid cases from the initial 174, i.e. without any missing values, could be used to complete the multivariable regression analysis. Although not significant in the univariable analysis, number of co-morbidities was also used in the multivariate analysis because of the allegedly high clinical relevance of this characteristic.

The best model of patient characteristics to predict the total costs of the demand for care contained the number of medications during hospitalisation, number of co-morbidities, number of complications, age and surgical specialty. This model explained $56.2 \%$ of the variance in the demand for care in terms of costs. The set of dummies for surgical speciality effectuate $49 \%$ of this variance. Total costs increased with $18 \%$ per additional complication (95\% CI 1 to 38\%; $\mathrm{p}=0.036$ ), while an additional medication caused a $3 \%$ increase in costs (95\% CI 1 to 5\%; $\mathrm{p}=0.007$ ). Per increasing year in age the costs increased with $0.5 \%$, but this was not statistically significant $(95 \% \mathrm{CI} 0$ to $1 \% ; \mathrm{p}=0.072)$. Unexpectedly, an additional co-morbid condition lowered the costs with 9\% (95\% CI -16 to $-3 \%$; $\mathrm{p}=0.005$; Figure 2). In addition, in a separate model of organisational factors surgical intervention and length of hospital stay were also found to be significant factors of total costs of care. This model explained $54 \%$ of the demand for care. Undergoing a surgical procedure nearly tripled total costs $(292 \%$; $95 \%$ CI 194 to $440 \%$; $\mathrm{p}<0.001)$, while an extra day of hospitalisation increased the costs with $8 \%$ (95\% CI 6 to $9 \%$; $\mathrm{p}<0.001$ ).

Bed occupation as proportion of the total number of available beds varied among wards from 53.2 to $70.5 \%$, while the percentage of optimum staffing in FTEs per ward ranged from 93.4 to $96.6 \%$ (Table 4). The investigators did not find any relation between a higher FTE occupancy or lower bed occupancy and more time spent on care. Hence, we could not detect a substantial influence of the availability of resources on demand for care.

From our random checks of the completeness of data recordings the investigators appreciated that nurses recorded 59 to $96 \%$ of their times spent per patient. Physicians stated a registration of between 45 to $100 \%$ of their activities.

\section{Discussion}

A model was developed to explain the demand for care based on readily available patient characteristics. Number of medications during hospitalisation, number of co-morbidities, number of complications, age, surgical specialty, as well as undergoing a surgical intervention and length of stay significantly contributed to an increased demand for care. It is likely that these results are generalizable to other specialties because these are blanket factors, applicable to a broad patient population.

No significant associations were found between the patient's ASA class, nutritional status, admission type and their demand for care. This is partially in agreement with the results from other investigators [10], a weak but significant correlation $(\mathrm{r}=0.35 \mathrm{p}<0.0001)$ between admission type and nursing workload. For ASA class and nutritional status, no comparable evidence is available. ASA class appeared to be a promising influencing factor in the univariable analysis, but was found not significant in the multivariable analysis. Probably too few patients belonged to ASA class 3, because we found significant associations between ASA classes 1 and 2, and between 1 and 3, but not between classes 2 and 3 . Also delirium, pressure ulcers, patient isolation, and in- 
Table 3 Univariable and multivariable linear regression analysis of possible predictive characteristics

\begin{tabular}{|c|c|c|c|c|c|c|c|c|c|}
\hline \multirow[b]{2}{*}{ Characteristic } & \multirow[b]{2}{*}{ N (\%) } & \multirow[b]{2}{*}{ Mean (SD) } & \multirow[b]{2}{*}{ Range } & \multicolumn{3}{|l|}{ Uni-variate } & \multicolumn{3}{|l|}{ Multi-variate } \\
\hline & & & & Estimate (B) & $95 \% \mathrm{Cl}$ & P-value & Estimate (B) & $95 \% \mathrm{Cl}$ & P-value \\
\hline Age & & $57.2(16.6)$ & $19-87$ & 0.004 & $0.001-0.007$ & 0.004 & 0.002 & $0.000-0.005$ & 0.072 \\
\hline Surgical Intervention performed & $167(96)$ & & & 0.594 & $0.351-0.837$ & $<0.001$ & 0.466 & $0.288-0.643$ & $<0.001$ \\
\hline Gender (males) & $99(56.9)$ & & & -0.015 & $-0.118-0.870$ & 0.767 & & & \\
\hline Number of co-morbidities & & $1.47(1.68)$ & $0-9$ & 0.000 & $-0.031-0.030$ & 0.978 & -0.038 & $-0.064-0.012$ & 0.005 \\
\hline Number of complications & & $0.21(0.60)$ & $0-4$ & 0.221 & $0.144-0.299$ & $<0.001$ & 0.072 & $0.005-0.139$ & 0.036 \\
\hline \multicolumn{10}{|l|}{ ASA-class } \\
\hline 1 & $41(26.8)$ & & & $\mathrm{RC}$ & & & & & \\
\hline \multirow[t]{2}{*}{2} & $89(58.17)$ & & & 0.168 & $0.057-0.279$ & 0.003 & & & \\
\hline & & & & $\mathrm{RC}$ & & & & & \\
\hline \multirow[t]{2}{*}{3} & $23(15.03)$ & & & 0.234 & $0.081-0.387$ & 0.003 & & & \\
\hline & & & & 0.067 & $-0.071-0.204$ & 0.339 & & & \\
\hline BMl at admission & & $26.43(5.37)$ & $17.2-53.6$ & -0.006 & $-0.015-0.003$ & 0.189 & & & \\
\hline Nutritional status & & $2.28(5.78)$ & $0-50$ & 0.018 & $0.010-0.026$ & $<0.001$ & & & \\
\hline Delirium during hospitalisation & $3(0.7)$ & & & & & & & & \\
\hline \multicolumn{10}{|l|}{$\begin{array}{l}\text { Pressure ulcer } \\
\text { acquired during hospitalisation }\end{array}$} \\
\hline grade 1 & 0 & & & & & & & & \\
\hline grade 2 & $1(0.6)$ & & & & & & & & \\
\hline grade 3 & $1(0.6)$ & & & & & & & & \\
\hline grade 4 & 0 & & & & & & & & \\
\hline \multicolumn{10}{|l|}{ Isolation } \\
\hline barrier & $2(1.15)$ & & & & & & & & \\
\hline strict isolation & 0 & & & & & & & & \\
\hline Survival & $174(100)$ & & & & & & & & \\
\hline $\begin{array}{l}\text { Number of medications } \\
\text { during hospitalisation }\end{array}$ & & $8.51(5.07)$ & $0-26$ & 0.031 & $0.022-0.040$ & $<0.001$ & 0.013 & $0.004-0.023$ & 0.007 \\
\hline Admission type & & & & -0.210 & $-0.360-0.061$ & 0.006 & & & \\
\hline home & $152(87.36)$ & & & & & & & & \\
\hline emergency & $22(12.64)$ & & & & & & & & \\
\hline \multicolumn{10}{|l|}{ Discharge type } \\
\hline home & $163(93.7)$ & & & & & & & & \\
\hline other & $11(6.32)$ & & & & & & & & \\
\hline Length of Stay & & $8.11(6.85)$ & $1-45$ & 0.034 & $0.028-0.039$ & $<0.001$ & 0.032 & $0.027-0.037$ & $<0.001$ \\
\hline \multicolumn{10}{|l|}{ Surgical specialty } \\
\hline TRAUMA & $4(2.3)$ & & & $\mathrm{RC}$ & & & & & \\
\hline URO & $21(12.07)$ & & & 0.776 & $0.511-1.042$ & $<0.001$ & 0.760 & $0.500-1.021$ & $<0.001$ \\
\hline ORTHO & 49 (28.16) & & & 0.758 & $0.505-1.012$ & $<0.001$ & 0.706 & $0.461-0.950$ & $<0.001$ \\
\hline ABDO & $55(31.06)$ & & & 1.152 & $0.900-1.405$ & $<0.001$ & 1.005 & $0.755-1.255$ & $<0.001$ \\
\hline SHORT & $14(8.05)$ & & & 0.644 & $0.368-0.920$ & $<0.001$ & 0.623 & $0.350-0.896$ & $<0.001$ \\
\hline PLAST & $12(6.9)$ & & & 0.622 & $0.381-0.943$ & $<0.001$ & 0.610 & $0.339-0.882$ & $<0.001$ \\
\hline VASC & $11(6.32)$ & & & 0.786 & $0.502-1.071$ & $<0.001$ & 0.738 & $0.456-1.020$ & $<0.001$ \\
\hline ORAL & $8(4.6)$ & & & 0.679 & $0.380-0.977$ & $<0.001$ & 0.664 & $0.383-0.946$ & $<0.001$ \\
\hline
\end{tabular}

$\mathrm{RC}=$ reference category.

Median total costs of the demand for care per patient were $€ 8,446$ and varied from $€ 815$ for trauma patients to $€ 82,780$ for G-I surgical patients (Figure 2). Surgical and diagnostic interventions contributed most to these costs. Nursing costs formed the largest part (76\%) of the personnel expenses; $€ 308$, vs. physicians $€ 56$, and paramedics $€ 2.70$ per patient, excluding the personnel costs for the surgical intervention. Median costs for surgical interventions were $€ 5,286$ (range: $€ 0-€ 21,111$ ). Median costs for diagnostic procedures were $€ 2,699$ and varied from $€ 372$ to $€ 74,567$ (Figure 3). 


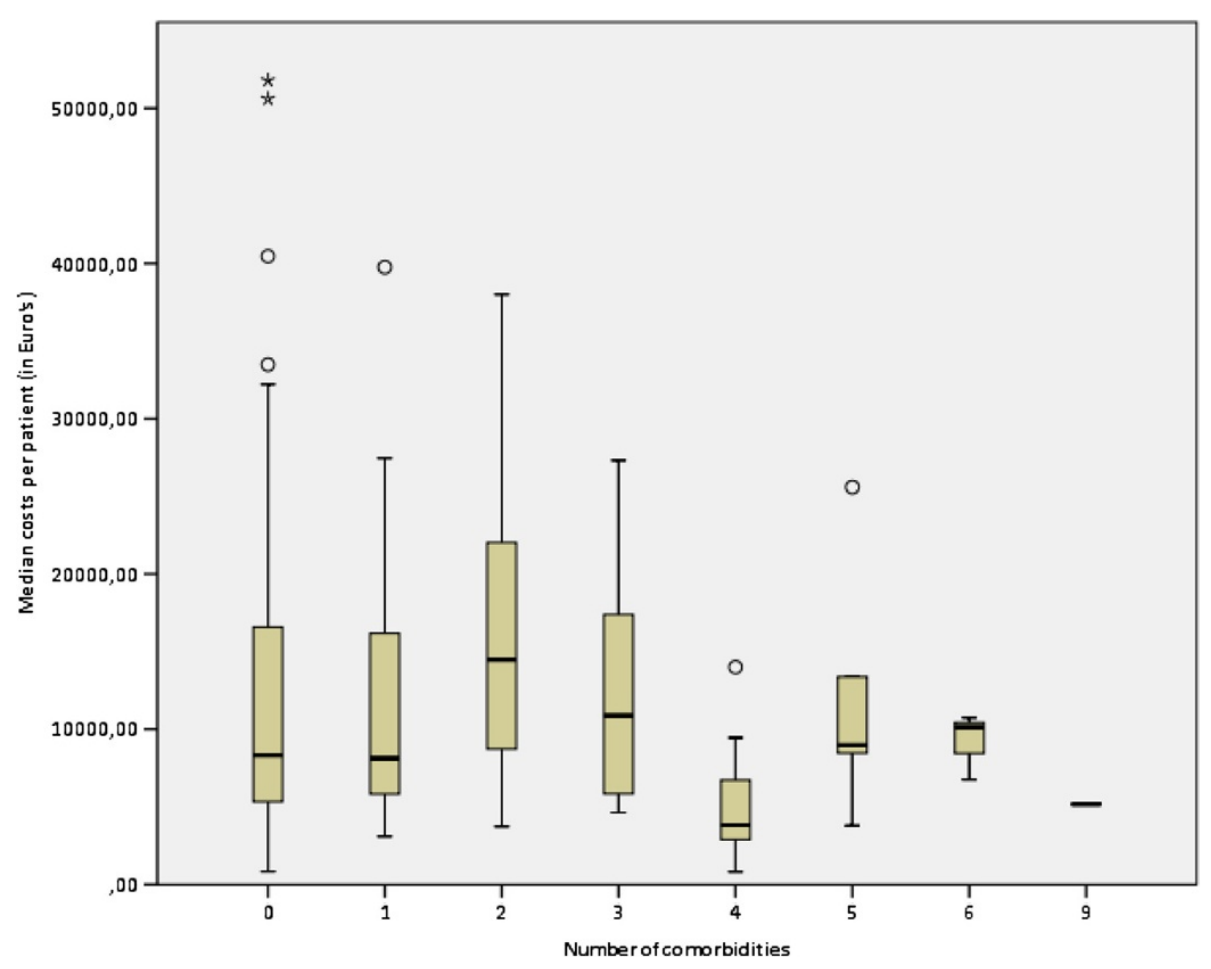

Figure 2 Box plots of median costs per patients of the demand for care per number of co-morbidities.

hospital mortality were not significantly associated with demand for care. This is likely because their incidence was quite low in our study, but not unusual for these wards. Furthermore, these factors are less useful as factors predicting the demand for care because they occur during hospitalisation and are not known beforehand. If they would contribute significantly to the model, they can still be useful as a managerial tool to monitor amount of care on a more aggregate level on wards to detect trends in time as to patients' demand for care.

Some nursing care models have found the case-mix groups (CMG) or Diagnosis Related Groups (DRGs) to be explanatory factors for the demand for nursing care $[6,9,11-13]$. In this study the investigators categorised the medical diagnoses at a more abstract level, i.e., surgical specialty, because of the large variety in diagnoses present. This specialty appeared relevant as it showed to be an important significant factor, explaining $49 \%$ of the variance in the demand for care in terms of costs.

The number of complications during hospitalisation also had a large influence on the demand for care. This number is likely to be related to co-morbidity and medication. Therefore, this number seems a sensitive indicator for the complexity of care and the following demand for care. Complexity is an important concept in research as to the demand for nursing care $[12,14]$. In the nursing realm, complexity has been measured by parameters like severity of illness [10] nature of nursing tasks $[12,18]$ and nursing diagnoses $[9,12]$. These variables had similar predicting values. The impact of complications on the demand for care was mainly due to the costs for diagnostic or therapeutic interventions, such as (redo) surgery to treat complications, and mostly occurred in patients undergoing gastro-intestinal surgery. This may be exemplary for the tertiary referral hospital in which this study was conducted.

The number of medications used during hospitalisation had less influence on the demand for care. No comparable evidence is available but this limited influence is possibly caused by the fact that medication is principally given to cure, and therefore associated with an increase in the demand for care. Also 'age' had less influence on the demand for care. This parameter nearly reached statistical significance $(P=0.072)$ in the multivariable model and was added because of its clinical relevance. Such poor associations were also found by other researchers $[8,9,12]$.

The negative association found between co-morbidity and demand for care may be because the severity of the various co-morbidities was not weighed in this study. Less severe co-morbidities may have been managed through medication, while patients with more severe co-morbidities were less likely to undergo surgery. This is confirmed by the study of Gijsen et al. [19]. They proposed the Charlson Comorbidity Index (CCI) to operationalise the severity of the co-morbidity. 


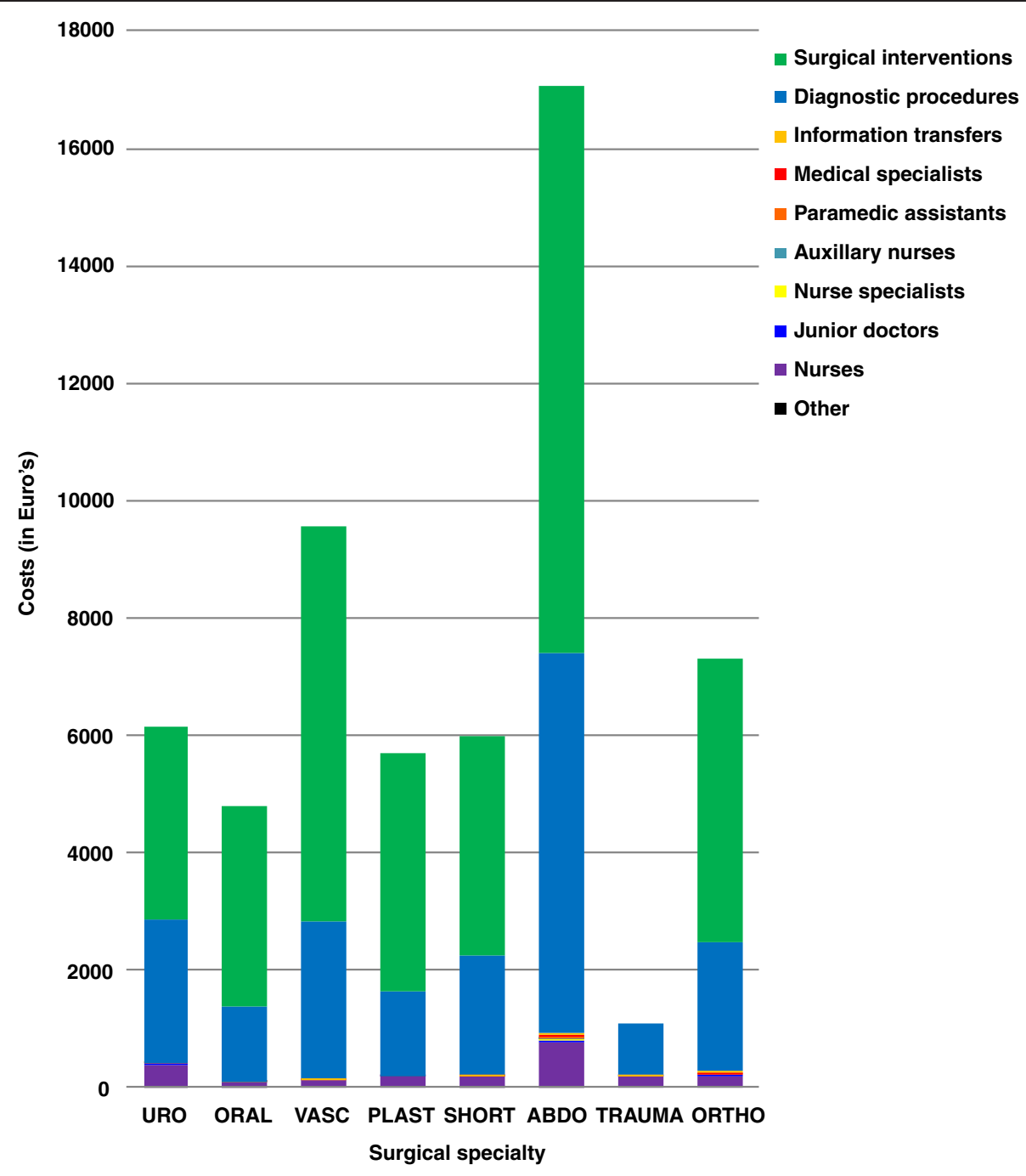

Figure 3 Median costs per patient of the demand for care per surgical specialty.

Table 4 Bed occupation and available FTEs during data collection

\begin{tabular}{lccc}
\hline Unit & $\begin{array}{c}\text { Bed occupation } \\
\text { \% }\end{array}$ & FTE $^{\mathbf{1 , 2} 3}$ & Time $^{\mathbf{4}}$ \\
\hline Short stay \& Urology & 60.29 & $95.08 \%$ & $32: 19: 06$ \\
Vascular and Plastic surgery & 56.63 & $93.62 \%$ & $29: 53: 37$ \\
G-I surgery & 65.86 & $94.85 \%$ & $67: 44: 50$ \\
G-I surgery and Oral \& & 70.53 & $93.44 \%$ & $63: 12: 02$ \\
Maxillofacial surgery & & & \\
Trauma surgery & 53.20 & $96.58 \%$ & $30: 03: 24$ \\
Orthopaedic surgery & 62.09 & $93.55 \%$ & $35: 29: 41$
\end{tabular}

1: Bed occupation (realised/available beds) during study period.

2: Mean of February and March 2010.

3: $100 \%$ (optimum personnel staffing) minus absence.

4: Mean total time spent per patient during hospitalisation.
Also, undergoing a surgical intervention and length of hospital stay were significant factors associated with the demand for care. This seems obvious, given the additional costs of surgery and of each extra day spent in the hospital. Previous studies have shown this is likely to be related to the severity of the patient's illness and therefore their demand for care $[2,10,12]$.

Some limitations of this study should be discussed. First, the investigators calculated and modelled the care the patients received, which may not be commensurate with what they needed. We did check that the results of our study represented demand for care rather than the mere usage of personnel and resources. The delivered care was independent of bed occupancy and available personnel. This suggests that indeed the demand for care was measured instead of offered resources. In retrospect, the investigators might also have appreciated 
whether the care given had met the patient's expectations and had cured or relieved their disorder.

Second, the investigators used a diversity of input, structure, process, and outcome variables in the model. As mentioned earlier, variables occurring during hospitalisation are unknown beforehand and therefore not useful as predictive factors. It seems plausible to use input variables for the explanatory model and use process and structure variables as specialty-specific or centre-specific characteristics, e.g. undergoing a surgical intervention, level of education $[7,8]$, or organisational factors [12,13], in an additional model. Furthermore, the success of the care given could also have been estimated, e.g. by measuring outcome variables as the number of complications or readmissions within 30 days after dismissal or by appreciating the quality of care [8]. This was beyond the possibilities of the present study, but will be incorporated in a recently started follow-up study among Dutch top-clinical hospitals.

Third, the investigators took for this study an innovative approach to measure the demand for care by time and motion research. This method was performed with rigour to collect data on individual patient contacts by professionals. Otherwise, continuous time and motion research provides precise results only if the professionals involved are willing to accurately record the time spent. The investigators found under-recording of time data, predominantly among doctors, resulting in an under-reporting of the total costs involved. Although this will have weakened the power of our model to predict demand for care, there was no reason to suspect selective under-recording that would have influenced the ability to detect predictive characteristics. It may explain, however, that the demand for care in our model appeared determined by the costs of the surgical and diagnostic interventions rather than the costs of personnel outside the operating theatre. As the investigators could not incorporate all costs at the same level of detail (e.g. overhead cost on wards or surgical interventions were not taken into account), a representative estimate was used of the costs for (para)medical and nursing care during admission. However, the overhead costs are likely to be proportional to the personnel costs we measured and therefore not influencing the outcome of our model.

Fourth, by expressing the demand for care as costs, the contribution of unpaid medical trainees to the patient care was not taken into account, although they deliver a substantial contribution to patient care in university clinics and affiliated hospitals. In addition, costs for overhead, patient transport, medication, material costs for surgical procedures in the operating theatre or on the nursing ward were not taken into account, while costs for ICU- and recovery stays were entered as fixed costs. Finally, no additional charges were included for surgical interventions during weekends, evenings and nights. Further detailing of these costs was beyond our possibilities but it is doubtful whether this would have had a major impact on the general outcome of our study.

\section{Conclusion}

A practical model was developed to explain the total demand and costs of care for surgical patients in a university hospital. The input for this model, age, number of co-morbidities, number of medications during hospitalisation, number of complications, surgical specialty, and length of hospital stay, can be derived from readily available data in hospital databases. The time and motion approach to estimating costs potentially provides an accurate assessment of the demand for care. This approach can be applied more broadly to the same ends.

It is worthwhile to explore this model in different populations and healthcare organisations. The results needs to be further explored, but can combined with population projections potential allow healthcare professionals and managers in policy making, i.e. informed planning and budgeting.

\section{Competing interest}

The authors declare that they have no competing interests.

\section{Authors' contributions}

$\mathrm{CO}, \mathrm{DU}$ and HV were responsible for the conception; CO and DU designed the study; CO, DU and HV were responsible for data collection; CO and DU analysed the data; $\mathrm{CO}$ and wrote the article; $\mathrm{CO}$ had primary responsibility for final content; HV, DG and PB were responsible for editing the article. All authors read and approved the final manuscript.

\section{Acknowledgements}

The investigators thank the many physicians, nurses, and paramedical personnel of the surgical departments for their effort to record their time spent on patient care, and the patients for participating in this study. The investigators are also grateful to the team that advised and daily supervised the collection of the PDAs and time data on the wards.

\section{Author details}

'Department of Quality Assurance \& Process Innovation, Academic Medical Centre, room A3-503, P.O box 22700, Amsterdam, DE 1100, The Netherlands. ${ }^{2}$ Amsterdam School of Health Professions, University of Amsterdam, P.O box 22700, Amsterdam, DE 1100, The Netherlands. ${ }^{3}$ Departments of Surgery, Academic Medical Centre, P.O box 22700, Amsterdam DE 1100, The Netherlands.

Received: 6 July 2012 Accepted: 31 January 2013

Published: 4 February 2013

\section{Reference}

1. Christensen K, Doblhammer G, Rau R, Vaupel JW: Ageing populations: the challenges ahead. Lancet 2009, 374:1196-1208.

2. Bostrom JM: Impact of physician practice on nursing care. Nurs Econ 1994 12:250-255.

3. Cullen DJ, Civetta JM, Briggs BA, Ferrara LC: Therapeutic intervention scoring system: a method for quantitative comparison of patient care. Crit Care Med 1974, 2:57-60. 
4. De Groot HA: Patient classification system evaluation. Part 1: Essential system elements. J Nurs Adm 1989, 19:30-35.

5. Bostrom J, Mitchell M: Relationship of direct nursing care hours to DRG and severity of illness. Nurs Econ 1991, 9:105-111.

6. Campbell T, Taylor S, Callaghan S, Shuldham C: Case mix type as a predictor of nursing workload. J Nurs Manag 1997, 5:237-240.

7. Diers D, Bozzo J: Nursing resource definition in DRGs. RIMS/Nursing Acuity Project Group. Nurs Econ 1997, 15:124-130.

8. Fagerström L, Rainio A, Rauhala A, Nojonen K: Validation of a new method for patient classification, the Oulu Patient Classification. J Adv Nurs 2000, 31:481-490.

9. Halloran EJ: Nursing workload, medical diagnosis related groups, and nursing diagnoses. Res Nurs Health 1985, 8:421-433.

10. Mion LC, McLaren CE, Frengley JD: The impact of patients' severity of illness and age on nursing workload. Nurs Manage 1988, 19:26-28. 30, 32-3.

11. O'Brien-Pallas $L$, Tritchler $D$, Till J: Variability in nursing workload within CMGs (case mix groups). Healthc Manage Forum 1989, 2:26-31.

12. O'Brien-Pallas L, Irvine D, Peereboom E, Murray M: Measuring nursing workload: understanding the variability. Nurs Econ 1997, 15:171-182.

13. Sermeus $W$, Delesie $L K$, Diya $L$, Lesaffre $E$ : Measuring the intensity of nursing care: making use of the Belgian Nursing Minimum Data Set. Int J Nurs Stud 2008, 45:1011-1021.

14. Soeken KL, Prescott PA: Patient intensity for nursing index: the measurement model. Res Nurs Health 1991, 14:297-304.

15. Morris R, MacNeela P, Scott A, Treacy P, Hyde A: Reconsidering the conceptualization of nursing workload: literature review. J Adv Nurs 2007, 57:463-471.

16. Fasoli DJR, Haddock KS: Results of an Integrative Review of Patient Classification Systems. Annu Rev Nurs Res 2010, 28:295-316.

17. Zheng K, Guo MH, Hanauer DA: Using the time and motion method to study clinical work processes and workflow: methodological inconsistencies and a call for standardized research. J Am Med Inform Assoc 2011, 18:704-710.

18. Goossen WT, Epping PJ, Van den Heuvel WJ, Feuth T, Frederiks CM, Hasman A: Development of the Nursing Minimum Data Set for the Netherlands (NMDSN): identification of categories and items. J Adv Nurs 2000, 31:536-547.

19. Giisen R, Hoeymans N, Schellevis FG, Ruwaard D, Satariano WA, van den Bos GAM: Causes and consequences of comorbidity: A review. J Clin Epidemiol 2001, 54:661-674.

doi:10.1186/1472-6963-13-42

Cite this article as: van Oostveen et al:: Explaining the amount of care needed by hospitalised surgical patients: a prospective time and motion study. BMC Health Services Research 2013 13:42.

\section{Submit your next manuscript to BioMed Central and take full advantage of:}

- Convenient online submission

- Thorough peer review

- No space constraints or color figure charges

- Immediate publication on acceptance

- Inclusion in PubMed, CAS, Scopus and Google Scholar

- Research which is freely available for redistribution 